\title{
Post partum haemorrhage: Prevalence, morbidity and management pattern in Dhulikhel Hospital
}

\section{Dongol AS ${ }^{1}$, Shrestha $\mathbf{A}^{1}$, Chawla CD $^{2}$}

${ }^{1}$ Lecturer, ${ }^{2}$ Professor, Department of Obstetrics and Gynaecology, Kathmandu University School of Medical Sciences, Dhulikhel, Nepal.

\begin{abstract}
Background: Post partum haemorrhage (PPH) is the leading cause of maternal death worldwide. PPH occurs in up to $18 \%$ of total births. Among different factors, $\mathrm{PPH}$ due to uterine atony is the primary and direct cause of maternal mortality comprising about $90 \%$.
\end{abstract}

Objective: The objective of the present study was to assess the prevalence, morbidity and management pattern of PPH in Dhulikhel Hospital.

Materials and methods: Hospital based retrospective study was carried out at Kathmandu University School of Medical Science, Dhulikhel Hospital from the period of January 2007 till October 2009. The study group included total of 60 patients. All women who had PPH both primary and secondary were studied. Information regarding total number of deliveries obtained from Obstetrics ward. The cases with PPH were identified and detail records were reviewed using standard format. The main outcome measures used for the analysis were amount of blood loss, cause of PPH and treatment methods.

Results: In Dhulikhel hospital, from January 2007 till October 2009 a total of 3805 deliveries took place. Out of which 60 women had PPH. The prevalence was 16/1000 deliveries. There are 41 (68.3\%) cases of primary PPH and 19 (31.7\%) cases of secondary PPH. PPH was found more in home deliveries, unbooked case and in multiparas. The mean blood loss was $1055 \mathrm{ml}$.

As an aetiology, retained placenta and retained placental bits of tissue was found in 37(61.7\%) cases, atonic uterus in 10 $(16.7 \%)$ cases, genital tract trauma in $8(13.3 \%)$, sepsis of genital tract in $3(5 \%)$, case of ruptured uterus in one case and a case of angle bleeding from previous uterine scar following caesarean section.

Among all 15 (25\%) cases underwent manual removal of placenta, 5(8.3\%) underwent controlled cord traction, 3 (5\%) underwent manual removal of placenta followed by check curettage in cases of retained placenta, $16(26.7 \%)$ cases were managed by check curettage for retained bits of placental tissue and membrane. Trauma in genital tract was managed by repair of trauma in $6(10 \%)$ cases. Hysterectomy was required in $3(5 \%)$ cases. Conservative management with uterotonics only required in $12(20 \%)$ cases.

Conclusion: Active management of third stage of labour can prevent PPH so delivery by skilled hand in hospital should be promoted. Secondary PPH besides primary can result in significant maternal morbidity. It also deserves similar attention.

Key words: Atonic uterus, Postpartum haemorrhage

$\mathrm{P}$ ost partum haemorrhage is the leading cause of maternal death worldwide ${ }^{1}$. 14 million women suffer from PPH every year. Among them 1,40,000 die and 1.6 million survive with long term disability due to anaemia $^{2}$. PPH occurs in up to $18 \%$ of total births ${ }^{3}$ Blood loss of more than a litre is considered physiologically significant and can result in hemodynamic instability ${ }^{4}$. Even with appropriate management, approximately 3\% of vaginal deliveries will result in severe PPH.

Among different factors, PPH due to uterine atony is the primary and direct cause of maternal mortality comprising about $90 \%$. Retained products of conception, trauma in genital tract and coagulation abnormalities are important causes of PPH. Sepsis of genital tract being the primary cause for secondary $\mathrm{PPH}^{5}$.

Variety of acceptable methods of treatment are available nowadays and are already proved to be safe and effective but still occasionally proves to be inadequate.

Correspondence

Dr. Dongol AS

Kathmandu University School of Medical Sciences,

Dhulikhel, Nepal 
Materials and methods

This hospital based retrospective study was carried out at Kathmandu University School of Medical Science, Dhulikhel Hospital from the period of January 2007 till October 2009. The study group included the women who had PPH amongst the women who underwent deliveries during the specified time period. All women who had PPH both primary and secondary were studied.

Information regarding total number of deliveries was obtained from Obstetrics ward. The cases with blood loss more than $500 \mathrm{ml}$ during vaginal delivery and more than $1000 \mathrm{ml}$ during caesarean section were identified and detail review of their records were carried out using standard format. Data recorded were age, parity, ANC, onset of labour, place of delivery, mode of delivery, amount of bleeding, duration of bleeding, causes of $\mathrm{PPH}$, resuscitation, transfusion and treatment methods.

The main outcome measures used for the analysis were amount of blood loss, cause of PPH and treatment methods.

The data collected were analyzed using analysis software SPSS. Statistical analysis was performed with the use of chi-square. A p-value of $<0.05$ was considered statistically significant.

\section{Results}

In Dhulikhel hospital, from January 2007 till October 2009 a total of 3805 deliveries took place. Out of which 60 women had PPH. The prevalence was 16 per 1000 deliveries. Mean age of the study population was 26.4 yrs. As per ethnic distribution, PPH was more common in Tamang i.e- 32 (53\%) followed by Chhetri 12 (20\%), Newar $10(16.7 \%)$ and Brahmin 6(10\%) respectively. There were $41(68.3 \%)$ cases of primary PPH and 19
(31.7\%) cases of secondary PPH. PPH was found to be more in unbooked cases $44(73.3 \%)$ than booked cases $16(26.7 \%)$.

Study also shows that PPH following home delivery was maximum 35 (58.3\%) followed by hospital delivery 18 $(30 \%)$ and health post delivery $7(11.7 \%)$.

PPH was seen maximum with spontaneous onset of labor 58(96.7\%) and less with induced labor 2(3.3\%). The mean blood loss was $1055 \mathrm{ml}$ with the range of 500 to $2100 \mathrm{ml}$.

Retained placenta and retained placental bits of tissue was found in $37(61.7 \%$ ) cases, atonic uterus in 10 $(16.7 \%)$ cases, genital tract trauma in $8(13.3 \%)$, sepsis of genital tract in $3(5 \%)$, case of ruptured uterus in one case and a case of angle bleeding from previous uterine scar following caesarean section.

Among total case of PPH $53(88.3 \%)$ required resuscitation and $7(11.7 \%)$ did not. Among 60 case $35(58.3 \%)$ patients required blood transfusion. 8 pint being transfused maximum.

$15(25 \%)$ of cases underwent manual removal of placenta, 5(8.3\%) underwent controlled cord traction and $3(5 \%)$ underwent manual removal of placenta followed by check curettage in cases of retained placenta. $16(26.7 \%)$ cases were managed by check curettage for retained bits for placental tissue and membrane. Trauma in the genital tract were managed by repair of trauma $6(10 \%)$ cases. $3(5 \%)$ cases required hysterectomy for post partum haemorrhage management. 12 (20\%) patients did not require surgical management and managed conservatively with uterotonics.

Table 1: Table showing type of PPH in booked and unbooked cases with type of PPH

\begin{tabular}{|l|c|c|c|}
\hline Type of case & Total No & Primary PPH (\%) & Secondary PPH (\%) \\
\hline Booked case & 16 & $6(37.5)$ & $10(62.5)$ \\
\hline Unbooked case & 44 & $35(79.5)$ & $9(20.5)$ \\
\hline
\end{tabular}

Table 2: Table showing PPH in different site of delivery

\begin{tabular}{|l|c|c|c|c|}
\hline & Home delivery & Health post delivery & Hospital delivery & Total \\
\hline Booked case & 1 & 0 & 15 & 16 \\
\hline Unbooked case & 34 & 7 & 3 & 44 \\
\hline
\end{tabular}

Table 3: Table showing type of PPH and parity

\begin{tabular}{|l|c|c|c|c|}
\hline & Primipara & Multipara & Grandmultipara & Total \\
\hline Primary PPH & 11 & 24 & 6 & 41 \\
\hline Secondary PPH & 6 & 13 & 0 & 19 \\
\hline
\end{tabular}


Table 4: Table showing type of PPH and Mode of delivery

\begin{tabular}{|l|c|c|c|}
\hline & Vaginal Delivery & Cesarean delivery & Total \\
\hline Primary PPH & 40 & 1 & 41 \\
\hline Secondary PPH & 16 & 3 & 19 \\
\hline
\end{tabular}

Table 5: Table showing cause of $\mathrm{PPH}$

\begin{tabular}{|l|c|c|}
\hline Cause of PPH & Frequency & Percentage (\%) \\
\hline Atonic Uterus & 10 & 16.7 \\
\hline Retained placenta and Retained placental bits of tissue & 37 & 61.7 \\
\hline Trauma & 8 & 13.3 \\
\hline Sepsis & 3 & 5.0 \\
\hline Angle bleeding following C/S & 1 & 1.7 \\
\hline Rupture Uterus & 1 & 1.7 \\
\hline Total & $\mathbf{6 0}$ & $\mathbf{1 0 0 . 0}$ \\
\hline
\end{tabular}

\section{Discussion}

This study was conducted at Dhulikhel Hospital, department of Obstetrics and Gynaecology form 2007 to 2009. Like in other studies the prevalence of primary $\mathrm{PPH}$ was also found to be higher at our centre ${ }^{6,7}$.

Atonic PPH remains the most important cause as is seen in other studies ${ }^{8}$.

Our studies showes retained placenta seems to be the culprit for primary PPH with $61.7 \%$ of patients followed by atonic $\mathrm{PPH}$ and traumatic $\mathrm{PPH}$ respectively. The percentage of $\mathrm{PPH}$ was more common in patients who were unbooked compared to our booked cases. The reason was active management of $3^{\text {rd }}$ stage being practiced in our hospital. Lalonde A et al in their study showed that active management of third stage of labour can prevent $\mathrm{PPH}^{9}$. Though our hospital caters its services to all ethnic population we noticed that $\mathrm{PPH}$ was more common in Mongolian race (Tamang) which is very similar to the study done by Pramila et.al ${ }^{7}$. Though we know that PPH is more common in grandmultipara by definition more than 5 deliveries, we found the prevalence to be higher in multiparas ( $>2$ deliveries) ${ }^{10}$.

The percentage of secondary $\mathrm{PPH}$ was $31.7 \%$ in our study. It is due to many patients undergoing home delivery without septic precaution. Almost all patients with secondary PPH underwent USG and found 68.4\% presented with retained bits of placenta and sepsis. Almost all cases received septic coverage before surgical management. We encountered a case of secondary PPH due to angle bleeding in uterine incision site following LSCS. All the patients with secondary PPH received septic coverage by I/V antibiotics. Another case of PPH was due to ruptured uterus and that case underwent hysterectomy.
In other studies cases of primary PPH due to retained placenta was managed by CCT whereas we managed $15(25 \%)$ with MRP $^{6,7}$. The reason was late presentation of our patients to hospital following home delivery.

Check curettage for management of PPH after resuscitation and septic coverage was done in 16 $(26.7 \%)$

Blood transfusion was given to total $30(50 \%)$ patients whose $\mathrm{Hb} \%$ was less than $7 \mathrm{gm} \%$ the reason for this being excessive blood loss due to various region, other reason being late presentation to hospital and their ANC $\mathrm{Hb} \%$ which itself was low. 35(58.3\%) patients required blood transfusion, maximum of 8 Units was transfused in patient with angle bleeding in uterine incision site following LSCS. Transfusion rate was comparatively higher in our study compare to study done by Pramila et.al ${ }^{7}$.

\section{Conclusion}

Active management of third stage of labour can prevent PPH so delivery by skilled hand in hospital should be promoted. Secondary PPH besides primary one can result in significant maternal morbidity. It also deserves similar attention.

\section{References}

1. Khan KS, Wojdyla d, Say L, Gulmezoglu AM, Van Look PF. WHO analysis of cause of maternal death: a systematic review. Lancet. 2006;367:1066-74.

2. Ronsmans C, Graham WJ. Maternal Mortality: Who, when, where and why? Lancet. 2006;368:1189-2000. 
3. Elbourne DR, Prendiville WJ, Carroli G, Wood J, Mc Donald S. Prophylactic use of Oxytocin in the third stage of labor. Cochrane Database Syst Rev. 2001;(4):CD 001808.

4. Bais JM, Eskes M, Pel M, Bonsel GJ, Bleker OP. Postpartum haemorrhage in nulliparous women: incidence and risk factors in low and high risk women. A Dutch population based cohort study on standard and severe post partum haemorrhage. Eur J Obstet Gynecol Reprod Biol. 2004;115:166-72.

5. Society of Obstetricians and Gynecologist of Canada. Advances in labour and Risk Management (ALARM). 5th edition. Canada: Society of Obstetricians and Gynecologist of Canada;1998.
6. Shah R, Karki C, Padhye SM. Experience with surgical option for managing atonic post-partum haemorrhage. NJOG. 2008; 3(1):10-3.

7. Pradhan P, Thapa Magar S, Lama S. Post partum haemorrhage in Teaching Hospital. NJOG. 2006; 1(1):26-9.

8. Moir JC. Post partum haemorrhage In: Moir, JC, editor. Munro Kerr's Operative Obstretics. London: Bailliere, Tindall and Cox; 1956.p.854-76.

9. Lalonde A, Daviss BA, Acosta A, Herschderfer K. Postpartum haemorrhage today. Int J Gynecol Obstet. 2006;94(3):243-53.

10. Gary Cunningham, Norman F. Gant, Kenneth J. Leveno, Larry C. Gilstarp III, John C. Hauth, Katharine D. Obstetrical Haemorrhage. Inc Williams Obstetrics. $21^{\text {st }}$ edition. USA: Mc Graw Hill; 2002.p. 635-63. 